\title{
IDÉIAS
}

\section{Repartir com Coerência: Desafio do Legislador}

Egídio Ferreira Lima

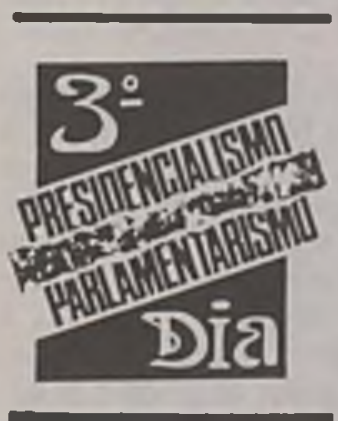

"Eu serei breve. $\mathrm{E}$ devo dizer inicialmente que é um privilégio viver neste país agora. Estamos numa fase fascinante. Tobias Barreto, já vai tanto tempo, dizia que esse

pais, esta nação, não teve a oportunidade de constituir, de elaborar o seu estado. O estado brasileiro, até hoje foi elaborado artificialmente por alguns poucos. Creio que é chegada a hora de elaborar o estado a partir da vontade da sociedade.

Há um despertar constante. E eu digo reiteradamente, a partir de 82 , que todos nós devemos nos conscientizar de que estamos vivendo numa revolução. A revolução não se caracteriza necessariamente pela insurreição, pelo conflito armado, ela é muito mais um processo evolutivo, uma ânsia coletiva e generalizada de alteraçōes de estrutura, de modernização. E quem acompanha o processo político neste pais de 82 para cá, e tem percepção, sente que estamos vivendo uma fase inusitada. Estamos vivendo uma revolução.

O Ministro Aluízio Alves promoveu esse simpósio com dois alcances que honram a sua percepção. Com o primeiro ele coloca bem o Governo, ele é ministro de Estado. E na hora em que se elabora, se processa uma nova Constituição, isentamente ele abre esse debate em nome do Governo, com um outro alcance que revela a sua perspicácia, a sua nitidez de consciência quanto ao processo político. Ele prepara o próprio governo para a reformulação, a modernização da administração pública que haverá de decorrer da

O Deputado Egidio Ferreira Lima é Deputado Federal pelo PMDB de Pernambuco, e Debatedor do 3. Dia.

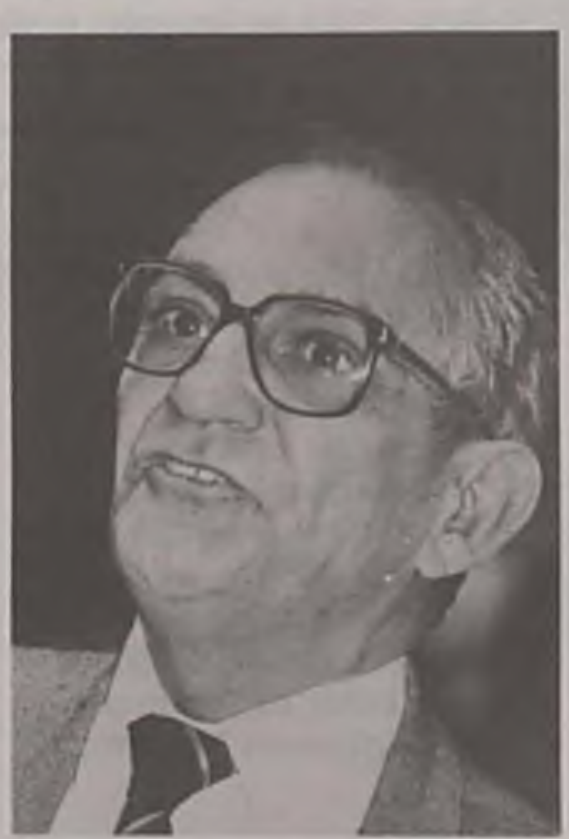

nova Constituição, da nova estrutura de estado.

O Deputado Ulysses Guimarāes declarou aqui, não faz pouco tempo, que a questão nuclear, na elaboração desse novo estado, é o sistema de governo. Ele é o centro do poder, da estrutura do estado. Não adianta arrolar garantias individuais, bem postas e precisas, não adianta definir bem como deverá ser a ordem econômica, não ađianta os comandos para a questão social, se você não tem uma boa, funcionável, moderna e precisa forma de governo. Um bom sistema de governo. Daí porque o debate de agora e a sua pertinência, parlamentarismo ou presidencialismo. Ouvimos, deleitados, o Prof. Thayssen e o Prof. Armando.

Foram pronunciamentos fundamentais numa hora em que o país, depois de passar por uma longa miscigenação, somente agora, pela primeira vez, pelo seu povo, vai constituir o seu estado. Eu vejo o sistema parlamentar de governo como re- volução, no caminhar da sociedade, no processo político de cada nação. Como bem disse o Prof. Armando, o presidencialismo é uma herança do absolutismo, do poder real. Até mesmo quando ele foi implantado nos EUA ele a foi por pura transplantação do sistema imperial, da imitação do rei, da saudade do rei da Inglaterra.

Ele não poderia persistir e não persistiu nos EUA. O sistema de governo existente nos EUA não é um sistema presidencialista, como em regra e teoricamente se entende este sistema. Pela própria evolução do processo político americano, ele assumiu conotaçōes bem claras de um sistema misto, porque o Congresso tem uma presença excessiva, e não sei até quando o Congresso americano vai continuar como mero censor, como mero obstáculo à ineficiência e aos momentos de falha do presidente americano.

Creio que ele também tenderá às suas origens, que são inglesas, para uma forma parlamentarista. Eu acho que é uma balela se dizer que não temos um meio histórico no Brasil, de que o parlamentarismo não encontraria um processo evolutivo na formação do Estado brasileiro. A fase mais tranqüila, mais estável do Império foi a do segundo reinado. E ali, sem que a Constituição de 1824 contivesse nenhuma norma referente ao sistema parlamentarista, ele começou a ser implantado, a se formar. $\mathrm{E}$ isso somente veio a ser imitado pelos teóricos e pelos militares que implantaram a República no Brasil, que imitaram, quase que literalmente e até na federação, o sistema americano.

Posteriormente nós tivemos a dolorosa experiência que se seguiu à renúncia do Presidente Jânio Quadros. E quem viveu aquele período, e muitos que estão aqui eu creio que viveram, se lembra de que o primeiro ministério parlamentarista do Chefe de Estado João Goulart foi o período de governo mais estável depois do governo Dutra, 


\section{IDÉIAS}

a partir de 1950. Durante um ano e seis meses viveu-se estavelmente neste país, e tivemos um ministério de alta densidade política e técnica, naquela fase. Somente quando o vice-presidente João Goulart foi em busca dos poderes de chefe de estado e de chefe de governo, quis ser o chefe da República num sistema presidencialista, ele se foi por terra. Aquela experiência, que é acidental, encontrou uma sementeira própria pela tendência e pela formação do próprio país.

Também não aceito a alegação de que não podemos instalar um sistema parlamentarista, no momento em que - conjuntural estaria a determinar a adoção da medida como remédio para o acidente de percurso da transição brasileira.

Ouvimos aqui, na narrativa e na exposição tão lúcida do Prof., como o conjuntural terminou levando a Alemanha a precisar o seu sistema de governo. Terminou acertando com uma Constituição de depois da Segunda Guerra Mundial. O fundamental é fazer com que a conjuntura, o periodo e fatores de momento não deformem, não tirem a precisão do sistema de governo. Não se ponham, ao se desenhar este sistema de governo, mecanismos casuísticos determinados tão-somente a atender interesses de grupos ou de pessoas que são sempre temporárias c eventuais. Também não aceito a alegação de que o país não está preparado, por não ter partidos e quadros políticos, para o parlamentarismo, além de que não temos uma burocracia permanente, capaz de atender a esta forma de governo. Como observam os conferencistas, como tão bem precisou o Senador José Fogaça, o parlamentarismo é causa, ele produz, ele fomenta os quadros políticos, ele cria quadros técnicos, profissionais da burocracia. Ele próprio estimula. Se esses argumentos fossem válidos, nunca, em parte nenhuma, o homem seria capaz de inovar, nunca, em nenhum momento.

É preciso ter na consciência de que da década de 50 para cá, o país mudou. Mudou de maneira extraordinária e gritante. Somente de lá para cá fizemos a revolução industrial. Ela praticamente foi toda feita neste periodo. Isso pro- vocou uma grande mudança de hábito, de concentração populacional. O Brasil era, na década de 40 e na década de 50 , um país rural, com uma população voltada para o campo. Hoje ele é um país urbanizado. Já se disse que esse pais era uma Belíndia, Bélgica junto com a India.

Mas tem um significado mais alto, de maior alcance. É que ao lado de faixas desenvolvidas, modernizadas, o país tem grandes misérias, grandes pobrezas.

\begin{tabular}{|} 
Não aceito a alegação de \\
que não podemos instalar \\
um sistema \\
parlamentarista, no \\
momento em que o \\
conjuntural estaria a \\
determinar a adoção da \\
medida como remédio para \\
o acidente de percurso da \\
transição brasileira. Temos \\
que evitar os casuismos \\
que deformam o sistema.
\end{tabular}

Essas grandes modificações estão a exigir que se quebre a crosta do passado, que se precise a estrutura do estado e que se modernize o sistema de governo.

Eu creio que este é um argumento fundamental para que ele comece efetivamente ser instalado. É que a partir de 50 também o país passou a ter uma comunidade cientifica com uma inteligência equiparável, relativamente, à inteligência de qualquer país da Europa Ocidental. Nós temos experts, pesquisadores, que não são meros acadêmicos, voltados para a realidade nacional em todos os campos. Temos politicólogos, pedagogos, economistas, sociólogos, e não temos uma centena. Temos milhares deles. $\mathrm{E}$ ai nós identificamos o grande milagre, o potencial em termos de evolução cultural; saímos de um regime autoritário longo, em que a atmosfera é rarefeita, e apesar disso essa inteligência se ampliou e se precisou. Temos hoje um quadro político, técni- co, científico neste país. $\mathrm{E}$ estes quadros são fundamentais para que se adote o sistema do parlamentarismo.

Ele, que é fruto do aperfeiçoamento das instituições políticas. Eu creio que cometeriamos uma grande falha, um erro talvez irreparável, se nessa hora não procurássemos partir para um sistema de governo assim, embora com as singularidades que o país está oferecendo.

O Prof. Armando chamou a atenção para um ponto fundamental, que é a pedra de toque que caracteriza ou que distingue o presidencialismo do parlamentarismo. É a possibilidade que tem o sistema parlamentarista de destituir o governo, de derrubar o governo, e olhem para o nosso passado, olhem para os vazios de poder de ontem e de hoje. Como ocupar e como resolver esse vazio de poder, quando, pela inapetência, por obstáculos, por problemas outros, o Presidente da República, que é chefe do estado e chefe do governo, não atende ao comando político e ao comando administrativo do país? A solução será o suicídio? Será a renúncia? Será a deposição? A nossa história está pontilhada desses fatos. Porque o regime de governo, o parlamento demite o governo e põe outro governo no seu lugar. A Itália, quando saiu da II Guerra Mundial estraçalhada nas suas instituições, não só de governo, na sua economia, na própria família, concebeu um sistema parlamentarista. No início parecia um sistema anárquico, ingovernável, não funcional. Ele andou, evoluiu e terminou se tornando um dos sistemas mais estáveis da Europa. E todos nós sabemos dos grandes problemas que a Itália tem, como a máfia, que é um problema longo na sua história, um estado dentro do estado. Não é fácil dirigir um estado tendo a cúria como outro estado ao seu lado.

A Itália se tornou um país tão livre, de tanta liberdade que se tornou a meta do terrorismo. $\mathrm{E}$ as instituições italianas, os mecanismos destas instituições punem, perseguem os terroristas, e o regime não se abala.

Terminou criando e consolidando um sistema de governo estável, que resiste aos impasses e administra os conflitos da sociedade, o que é uma característica fundamental do regime democrático. 


\section{IDÉIAS}

Ao lado disso fez com que a sua economia evoluisse, fez a reforma agrária, modernizou a sua agricultura, fez no norte, depois no sul, que era mais difícil. E já hoje é a terceira economia da Europa. Superou agora, de um ano para cá, a Inglaterra, Alemanha, França e Itália.

Creio que é o momento de pensar no que tem sido o nosso pais, as dificuldades de comando do estado, de exercício da administráção, de administração dos nossos conflitos e pensar no sistema de governo. É certo que temos o problema militar, que não vai se resolver com uma penada na Constituição, em que só a evolução concorrerá para que ele seja dirimido, só a consciência por parte do militar, a aceitação por parte dele, dos riscos, os tantos riscos de uma democracia plena, modificarão a ameaça e a deformação, divisão do estado, dos militares. No regime, num sistema parlamentarista, naturalmente os militares tenderão a ser levados para o seu papel profissional.

Essa mesa, Ministro Aluizio Alves, tem aqui V.Exa. com essa visão do ontem, e do hoje, e do amanhã que está muito próximo, tão próximo que se assoberba sobre o presente, nos inquietando a todos. As tensões que estamos vivendo, as noites não dormidas não me surpreendem, elas estavam no caminho da história do Brasil para agora e para esse momento.

Saímos de um longo regime autoritário em 15 de janeiro de 85. Até ali tinhamos instituiçōes autoritárias, ditatoriais, mas úteis ao funcionamento do regime autoritário. A partir de então não temos instituição nenhuma. E não é fácil conduzir um país como o Brasil, com a sua ânsia de novo, pulando na rua sem instituições. Ao lado disso devemos ter consciência de que estamos com a Constituinte a funcionar aqui, nesta Casa. E uma Assembléia Nacional Constituinte, porque desconstitui para constituir, ela cria instabilidade politica, e muitas das instabilidades que estão aí no país agora decorrem, também, da presença rica da Constituinte. Tenhamos competência, coragem de ousar, equilíbrio nessa ousadia e chegaremos a dezembro e, por certo, teremos transposto a fase mais aguda e de maior risco dessa transição. Eu não tenho indagações a fazer. Eu fiquei satis-

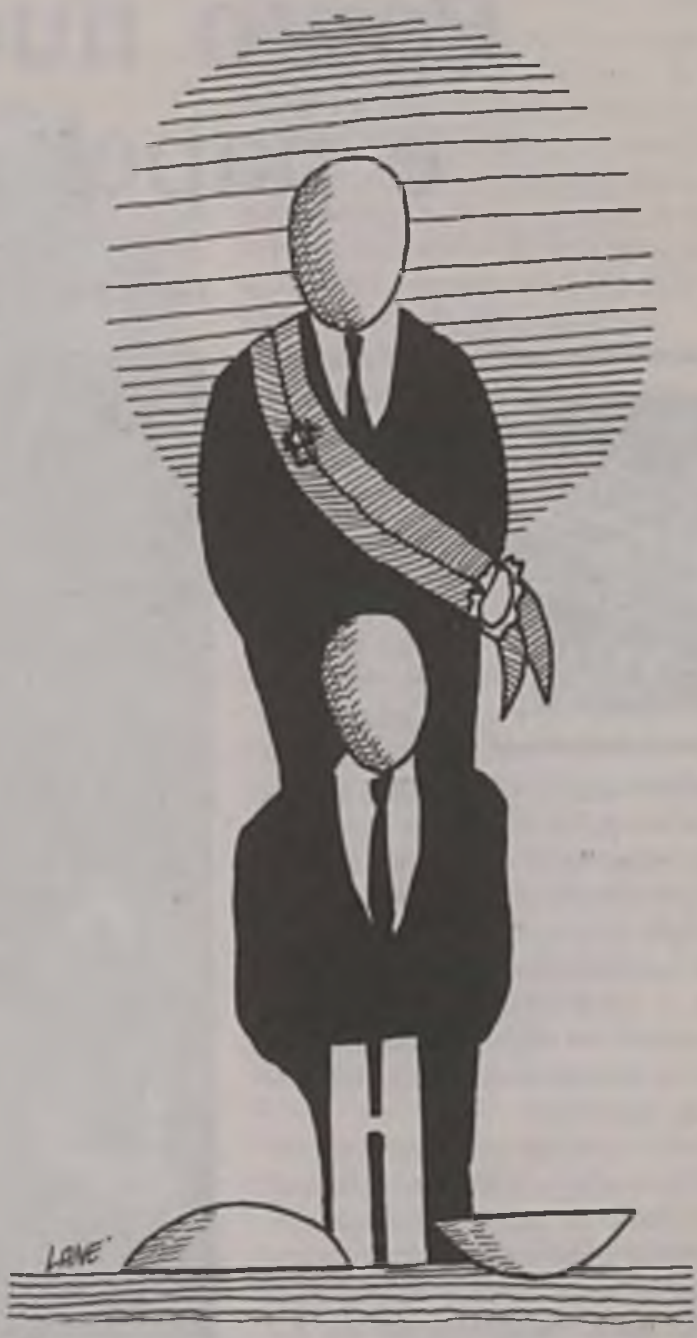

\section{Se buscarmos formas de distribuição de \\ competências entre o chefe de Estado e o chefe do}

Governo creia que logo, a partir de janeiro, começaremos a entrar na fase de grande fertilidade neste País. A partir daí, a administração poderá reaparelhar-se.

feito e até gratificado com as exposiç̋̄es. Quero apenas dizer que o nosso engenho, e aí vai ser primeiro o engenho do Senador José Fogaça, estabelecerá o equilíbrio entre um chefe de estado eleito pelo voto popular, com uma carga imensa de legitimidade, como bem salientou o Prof. Armando, e o chefe de governo.

Devemos buscar formulas que possam estabelecer a perfeita harmonia entre a distribuição das competências desse chefe de estado e desse chefe de governo. $\mathrm{E}$, se fizermos isso, eu creio que logo logo, a partir de janeiro, começaremos a entrar na fase de grande fertilidade neste pais. E que a partir dai, num tempo mais imediato, o Ministro Aluízio Alves vai ter um grande trabalho para aparelhar a administração pública criando aquela burocracia permanente, que é importante para o próprio funcionamento do sistema parlamentarista. 